\title{
Estimation of gillnet and hook selectivity for Carangoides fulvoguttatus (Forsskal, 1775) captured off Kanyakumari coast of India
}

\author{
A. BALASUBRAMANIAN ${ }^{1}$, B. MEENAKUMARI ${ }^{2,3}$, P. PRAVIN $^{2,4}$, K. DHANAPAL $^{5}$, \\ M. R. BOOPENDRANATH ${ }^{2}$ AND K. ERZINI ${ }^{6}$ \\ ${ }^{1}$ Fisheries Research Station, Sri Venkateswara Veterinary University, Undi - 534 199, West Godavari District \\ Andhra Pradesh, India \\ ${ }^{2}$ ICAR-Central Institute of Fisheries Technology, Kochi - 682 029, Kerala, India \\ ${ }^{3}$ National Biodiversity Authority, Chennai - 600 113, Tamil Nadu, India \\ ${ }^{4}$ Indian Council of Agricultural Research, New Delhi - 10 001, India \\ ${ }^{5}$ College of Fishery Science, Muthukur - 524 344, Andhra Pradesh, India \\ ${ }^{6}$ University of Algarve, Estrada da Penha - 8005-139, Portugal \\ e-mail:absmanyan@yahoo.com
}

\begin{abstract}
Selectivity and fishing powers of multi-mesh gillnets with mesh sizes of 13.5, 14, 14.5 and $15 \mathrm{~cm}$ and hooks No. 5, 6, 7 and 8 were studied using the experimental catch data of the carangid Carangoides fulvoguttatus (Forsskal, 1775). The selectivity curves, parameters and residual plots for different models viz., normal scale, normal location, log-normal, gamma and bi-normal models were produced applying the SELECT (Share Each Length Class Total) methodology which has been incorporated in the software GILLNET (Generalised Including Log-Linear N Estimation Technique). The models were evaluated using the statistical tools viz., model deviance, dispersion parameter and residual plots to determine the best fit of the selectivity data. The uni-normal model, normal scale was found as best fit for the gillnet catch data while bi-normal was identified as suitable model for the hook catch data. The mesh size of $14.5 \mathrm{~cm}$ and hook No. 5 performed better than the other modeled meshes and hooks respectively. Gillnet selectivity data did not converge into bi-normal model due to single mode of capture. However, the hook catch data converged into bi-normal model with two modes of selection curve. Over dispersion was found common in catch data obtained from both gears due to larger size of fishes caught and demonstrated lack of fit in both selection data.
\end{abstract}

Keywords: Carangid, Fishing power, Gillnet, Hook, SELECT, Selectivity

\section{Introduction}

Knowledge on selectivity of various fishing gear is important for the management, conservation and optimum exploitation of fishery resources. The selectivity models for trawls and gillnets are well standardised but for the hook, the standard pattern of selectivity curve is not yet known (Otway and Craig, 1993). Estimation of selectivity parameters and selection curves for hooks vary with models as well as species. Alverson et al. (1994) stated that depletion of fishery resources is mainly due to employment of non-selective fishing gears. Wide variety of larger carangids occur along the south-east coast of India and they are fished by a variety of gears especially trawl nets, drift gillnets and hooks. These gears are not yet standardised for optimum size capture of larger carangids. Total marine fish production of Tamil Nadu State for the year 1998-99 was 3,77,483 t Kanyakumari District contributed 38,316 t $(10.15 \%$ of total Tamil Nadu production) and ranked fifth in fish production in the state (Anon., 1999). The catch obtained from gillnet from Kanyakumari District was 10,046 $t$ and catch from line fishing was 19,279 t (Anon., 1999). Carangids receive good market value due to its size and consumer preference. However, so far no selectivity study has been conducted in this region for large carangids. It is essential to study the efficiency and selective nature of the gears employed for capturing these fishes as they have impact on size structure of the existing fish population. The objective of the present study was to determine the selectivity of multifilament gillnets and hooks employed for capturing the larger carangid species along the Kanyakumari coast in South India.

\section{Materials and methods}

Gillnet selectivity study was conducted with mesh sizes of 13.5, 14.0, 14.5 and $15.0 \mathrm{~cm}$ from September 2002 to April 2004 while the hook selectivity study was conducted with hook sizes of No. 5, 6, 7 and 8 during 
the period from June 2003 to 2004 in the Kanyakumari coast of Tamil Nadu, India. Location of the study area for gillnet operation was between $08^{\circ} 01.145^{\prime} \mathrm{N} ; 077^{\circ} 49.137^{\prime} \mathrm{E}$ and $08^{\circ} 00.821^{\prime} \mathrm{N} ; 077^{\circ} 45.192^{\prime} \mathrm{E}, 13$ nautical miles away from the shore. The fishing ground chosen for the study was the ground where the fishermen fish traditionally, characterised with bottom topography of rocks and corals having a depth range of 30 to $60 \mathrm{~m}$. Hook selectivity study was conducted in another traditional fishing ground located around $08^{\circ} .02 .425^{\prime} \mathrm{N} ; 077^{\circ} .34 .590^{\prime} \mathrm{E}$ and 2.45 nautical miles off Kanyakumari, having depth range of 15 to $25 \mathrm{~m}$.

The experimental gillnets used in the study were analogous in all respects with the net used by local fishermen having mesh size of $14 \mathrm{~cm}$. Total length of the net was 2,700 $\mathrm{m}$ and comprised of randomly arranged 36 gangs with chosen mesh size. The depth and length of each gang was 80 and 1000 meshes respectively. Nets were made up of multifilament nylon twine with RTex value of 737 and 786 for the mesh sizes 13.5, 14 and $14.5,15 \mathrm{~cm}$ respectively. The nets were hung to the double lined head rope (6 $\mathrm{mm} \mathrm{dia)}$ and 288 PVC floats (100 $\mathrm{mm}$ dia, $20 \mathrm{~mm}$ thickness) were attached to the head rope. A master float of $280 \times 280 \times 190 \mathrm{~mm}$ ( $\mathrm{L} \times \mathrm{B} \times \mathrm{H})$ made up of polystyrene was attached at both ends of each unit. The hanging ratio of the nets ranged from 0.5 to 0.56 .

Nets were operated by the local fishermen in the traditional fishing ground from FRP boat having length over all (LOA) of $8.4 \mathrm{~m}$. After every haul, mesh panels were rearranged randomly to minimise the bias and sampling error. Nets were drifted along with the boat for 4-6 $\mathrm{h}$ after mid-night and hauled before dawn.

Similarly, the drift hand lines with experimental hook sizes viz., No. 5, 6, 7 and 8 were operated. Of these hooks, No. 7 is conventionally used by the local fishermen. These hooks were Norwegian, Mustad, 'J' shaped flattened tinned round-bent type hooks (2315 oval). The dimensions like, height (shank length), gap (width), maximum width (maximum gap) and depth (throat) were measured for 10 pieces of hooks to get mean of the dimensions of the hooks with standard deviation. The mean size (shank height multiplied with width) of the hooks of No. 5, 6, 7 and 8 were $1308.69,1061.8,878.9$ and $681.79 \mathrm{~mm}^{2}$ respectively.

Fabrication of hand line was done locally with the help of identified fishermen. Totally four lines with different thickness were used to attach the hooks. Lines were made up of PA 6.6 (Nylon) monofilament. Diameter of the lines used were 2, 1.7 and $0.8 \mathrm{~mm}$. At the end of each hand line, three hooks of similar size were tied using $0.5 \mathrm{~mm}$ thick wire. The hooks were randomly changed in every fishing operation throughout the study to avoid interaction between hook sizes and bias during sampling in different strata with different hooks. Length of the first line was $150 \mathrm{~m}$ and sinker was not used, facilitating drifting in the surface water. Length of the second line was $125 \mathrm{~m}$ and had weight of $100 \mathrm{~g}$ which was tied $20 \mathrm{~m}$ away from the end of line. Length of third line was $90 \mathrm{~m}$ and weights of 300 and $200 \mathrm{~g}$ were attached to this line at a distance of 75 and $25 \mathrm{~m}$ respectively from the end of the line. The fourth line was selected with a length of $60 \mathrm{~m}$ and weights of 1000 and $300 \mathrm{~g}$ were attached to the line at a distance of 40 and $15 \mathrm{~m}$ respectively. Weights used were mild steel balls or stones. Similarly equivalent quantities of floats were crudely added to place the hooks in the particular strata. Three sets of hand lines were fabricated and operated from catamarans by the local fishermen for few hours as done in gillnet operation.

After hauling out both the gears, the catches of Carangoides fulvoguttatus (Forsskal, 1775) were sorted out, based on mesh and hook-wise and stored in separate containers. After bringing the catch to the shore, morphometric measurements like total length (TL), fork length (FL), gill girth $(\mathrm{Gg})$, gilled girth $(\mathrm{Gr})$, maximum girth (Gmax), individual weight and total weight of catch were recorded. Measurement of lengths and girths were taken to the nearest $\mathrm{cm}$ and $\mathrm{mm}$ respectively and weight to the nearest $\mathrm{g}$.

Mesh and hook selectivity parameters were estimated using the software GILLNET (Generalised Including Log-Linear N Estimation Technique) developed by CONSTAT (1998) which included the Millar's SELECT (Share Each Length Class Total) methodology (Millar, 1995). This methodology includes the maximised log-likelihood function and the function incorporates five different models under two divisions of uni-normal and bi-normal. The uni-normal function comprises Normal location (where modal length is proportional to mesh sizes but with fixed spread of the curve), Normal scale, Log-normal, Gamma and Bi-normal.

All the models follow Baranov's principle of geometric similarity (Baranov, 1948) except normal location curve. All these functions were used to estimate selectivity parameters of gillnet and hook and to get selection curves for the catch data.

In this method, the catch data collected from both gillnet and hooks were fitted twice to the above selectivity functions under the assumptions of equal fishing power and fishing power proportional to mesh/hook size (Millar and Holst, 1997). Further, the residual plots were obtained by plotting mesh/hook size against length class for every 
function under both the assumptions. Degrees of freedom (DF) was calculated by number of length class multiplied by number of mesh/hook sizes used minus number of length class and number of parameters involved (Millar and Fryer, 1999). Model deviances (D) (likelihood ratio) for each fit was calculated for corresponding degrees of freedom.

After fitting all the functions, goodness of fit was evaluated using model deviance (D) (McCullagh and Nelder, 1989) and residual plots. The deviance was evaluated from the residual difference between the proportion of fish of particular length caught and the relative length obtained from the models. The model, which had less deviance value, was considered as better fit. Dispersion parameter (DP) was calculated for all the models fitted to the catch data of the species. It is mainly to study the kind of dispersion or spread or variance of the selectivity curve. After assessing the fits with above-mentioned statistical tools, the better-fit models obtained were further inspected from the concerned residual plots.

The better fit model obtained for the catch of C. fulvoguttatus caught from both gillnet and hook were further approximated to bi-normal model to find out the best fit of the data as suggested by Holst et al. (1994). Deviance, Degrees of freedom, Dispersion Parameter and residual plots were also determined for the bi-normal model and validated as did in the uni-normal models to find out the best fit of the selectivity data of the species studied.

\section{Results and discussion}

Total catch of C. fulvoguttatus obtained from four mesh sizes was 2227 nos. out of 140 hauls, of which, 349 specimens were caught from mesh size 13.5; 615 from
$14 \mathrm{~cm} ; 753$ from $14.5 \mathrm{~cm}$ and 510 from $15 \mathrm{~cm}$. The total catch obtained from four hook sizes was 524 nos. out of 76 hauls. Out of this, 101 specimens were caught from hook No. $5\left(1308.69 \mathrm{~mm}^{2}\right), 115$ from No. $6\left(1061.8 \mathrm{~mm}^{2}\right)$, 130 from No. $7\left(878.9 \mathrm{~mm}^{2}\right)$ and 178 from No. $8\left(681.79 \mathrm{~mm}^{2}\right)$. Total degrees of freedom (DF), standard deviation (SD), model deviance (D) and other selectivity statistics are given in Table 1.

Selection curves of all uni-normal curves were symmetrical in shape and almost similar in all the models without skewness in both the gears operated (Fig. 1 and 2). Among all the models, the normal scale yielded the smallest deviance value for both gillnets under the assumption of equal fishing power (653.51) and hooks under the assumption that the fishing power is proportional to hook size (100.17). As a rule of thumb, it could be understood that the normal scale was the better fit for both catch data since it yielded smallest deviance compared to other models. Significant difference was found between the uni-normal models $(\mathrm{p}<0.01)$ obtained for mesh study while it was not the case in hook selectivity models. Model deviance varied greatly between models as well as different assumptions except log-normal and Gamma models. The variation in the assumption in normal scale and normal location could be attributed to the difference in the fishing powers of the gears.

Estimated deviance values for the uni-modal models were substantially greater than their respective degrees of freedom. The general rule of the thumb is that the deviance should be less than degrees of freedom (Holst et al., 1994; Millar and Fryer, 1999). Deviance of all the models including better-fit model were evaluated by referring it to a chi-square distribution $\left(\mathrm{p}<0.01, \chi^{2}\right.$ test $)$ since justification or rejection of model should never be based on the deviance alone (Holst et al., 1994). Dispersion

Table 1. SELECT model parameter estimates for gillnet and hook selectivity for Carangoides fulvoguttatus

\begin{tabular}{|c|c|c|c|c|c|c|c|c|c|}
\hline \multirow{2}{*}{ Gear } & \multirow{2}{*}{ Model } & & \multirow{2}{*}{$\begin{array}{l}\text { Degrees of } \\
\text { freedom }\end{array}$} & \multicolumn{3}{|c|}{ Equal fishing power } & \multicolumn{3}{|c|}{ Fishing power $\alpha$ Mesh size } \\
\hline & & & & Parameters & $\mathrm{SD}$ & $\begin{array}{l}\text { Model } \\
\text { deviance }\end{array}$ & Parameters & $\mathrm{SD}$ & $\begin{array}{l}\text { Model } \\
\text { deviance }\end{array}$ \\
\hline \multirow[t]{5}{*}{ Gillnet } & Normal location & Fixed spread $(\mathrm{k}, \mathrm{s})$ & 121 & $(4.6538,7.4560)$ & $0.0368,0.1566$ & 693.16 & $(4.7126,7.4997)$ & $0.0365,0.1584$ & 691.39 \\
\hline & Normal scale & Spread $\alpha$ mj $(\mathrm{k} 1, \mathrm{k} 2)$ & 121 & $(4.7861,0.5239)$ & $0.0369,0.0115$ & 653.6 & $(4.8445,0.5208)$ & $0.0359,0.0112$ & 653.51 \\
\hline & Lognormal & Spread $\alpha$ mj $(m, s)$ & 121 & $(4.1306,0.1136)$ & $0.0080,0.0025$ & 724.22 & $(4.1432,0.1136)$ & $0.0079,0.0025$ & 724.22 \\
\hline & Gamma & Spread $\alpha$ mj $(k, a)$ & 121 & $(0.0585,80.1385)$ & $0.0025,3.5369$ & 686.41 & $(0.0585,81.1385)$ & $0.0025,3.5426$ & 686.41 \\
\hline & Bimodal & Spread $\alpha \mathrm{mj}$ & & & Not converged & & & & \\
\hline \multirow[t]{7}{*}{ Hand line } & Normal location & Fixed spread $(\mathrm{k}, \mathrm{s})$ & 43 & $(6.6174,16.9819)$ & $0.1109,1.0354$ & 120.95 & $(7.1212,18.0939)$ & $0.1412,1.2169$ & 136.98 \\
\hline & Normal scale & Spread $\alpha$ mj $(\mathrm{k} 1, \mathrm{k} 2)$ & 43 & $(7.3237,1.7123)$ & $0.1043,0.0886$ & 100.17 & $(7.7117,1.6594)$ & $0.1070,0.0805$ & 100.28 \\
\hline & Lognormal & Spread $\alpha$ mj $(m, s)$ & 43 & $(3.9345,0.2656)$ & $0.0209,0.0145$ & 105.88 & $(4.0050,0.2656)$ & $0.0247,0.0148$ & 105.88 \\
\hline & Gamma & Spread $\alpha$ mj $(k, a)$ & 43 & $(0.4615,16.3798)$ & $0.0500,1.5830$ & 102.42 & $(0.4615,17.3798)$ & $0.0501,1.6314$ & 102.42 \\
\hline & Bimodal & Spread $\alpha$ mj $(\mathrm{a} 1, \mathrm{~b} 1)$ & 40 & $(7.1629,1.5925)$ & $0.1166,0.0957$ & 96.12 & $(7.5047,1.5468)$ & $0.1255,0.0883$ & 96.07 \\
\hline & & $(\mathrm{a} 2, \mathrm{~b} 2)$ & & $(9.7338,0.1636)$ & $0.0518,0.1117$ & & $(9.7370,0.1639)$ & $0.0444,0.1080$ & \\
\hline & & $\mathrm{w}$ & & 1.0479 & 2.2065 & & 1.4046 & 2.8624 & \\
\hline
\end{tabular}




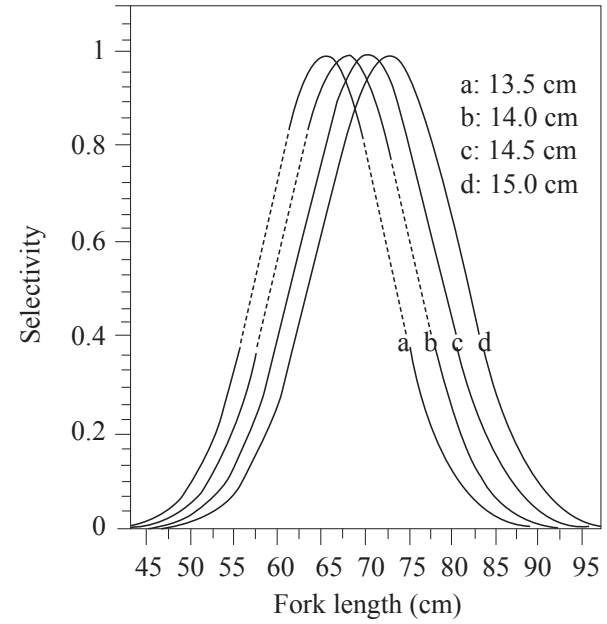

(a)

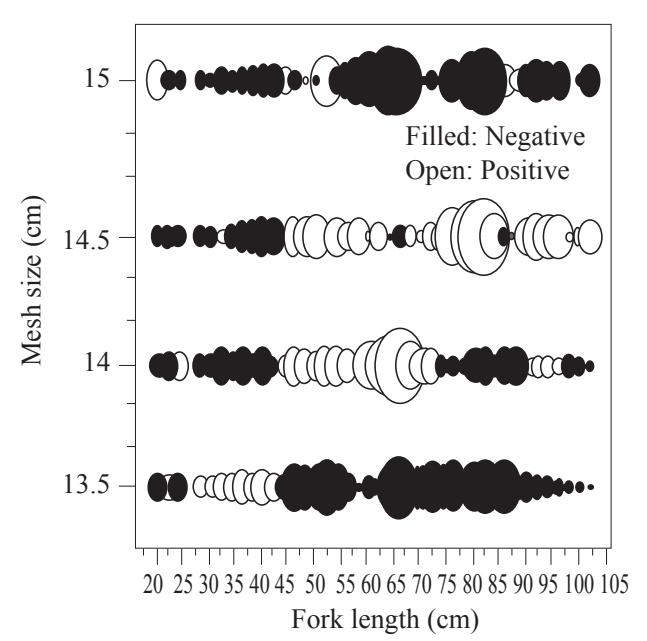

(b)

Fig. 1. Selective curve and residual plot of normal scale model (fishing power $\alpha$ mesh size) of Carangoides fulvoguttatus (area of the circle is proportional to square of the residual)

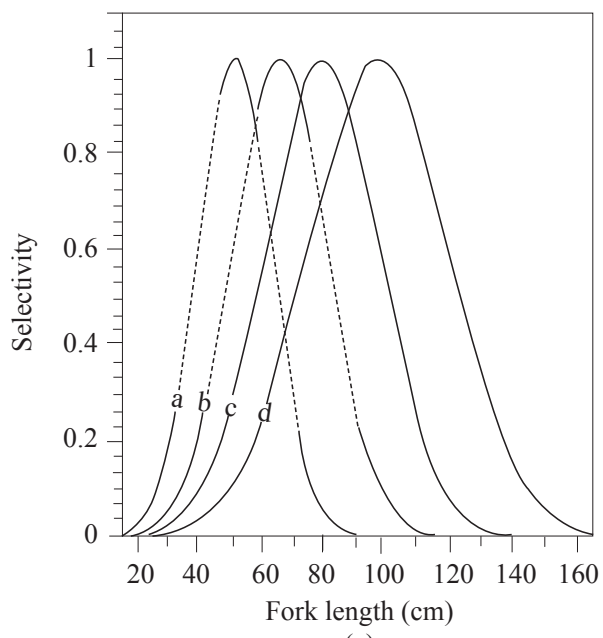

(a)

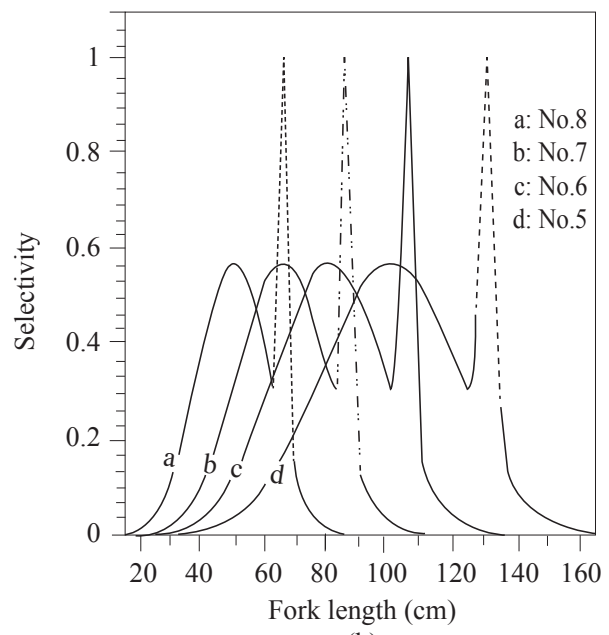

(b)

Fig. 2. Selectivity curves of better and best fit models for different hook sizes (a) Normal scale model (equal fishing power) - better fit Carangoides fulvoguttatus, (b) Bi-normal model (fishing power $\alpha$ hook size) - best fit Carangoides fulvoguttatus

parameter was greater than one in all the models including better-fit normal scale model fitted for both mesh (5.4) and hook (2.33) selection study. As the dispersion ratio was greater than one in all the cases, it could be interpreted as over-dispersion of data in all uni-normal models including better-fit model.

The over-dispersion endorsed the lack of fit of data and it might be due to poor choice of model or violation of the assumption underlying Poisson distribution (Miller, 1995). However, in general it is contemplation that over dispersion is common for many biological phenomena where individuals fail to behave independently (Holst et al., 1994) especially in the case of larger fishes. As the model deviance and dispersion parameter not alone determine the goodness of fit, the appearance of residual plots were also examined.

The residual plots of all the models obtained in both mesh and hook selection study for the species C. fulvoguttatus under both the assumptions also revealed that the normal scale model yielded better fit than any other models. Nevertheless, the better fit model also showed slight lack of fit due to the presence of less number of positive residuals larger in size, systematic arrangement of residual points in the residual plot instead of random presence, overlapping of residuals one over the other and the residual value was not within the range of '2' (Millar and Holst, 1997). It indicated that the better fit normal scale model also did not give good fit under Poisson distribution (Holst et al., 1994). 
While calculating the selectivity of multi-meshed gillnet, the size of mesh is generally considered, but not the size/length of the net. Size of the mesh determines length of the net and size of the net also influences the probability of selection in capturing the fish. Hence, estimation of fishing power of the gear is also considered as important in estimating the selectivity (Fujimori and Tokai, 2001).

The residual plot (Fig. 1) exhibited that the mesh size of $14.5 \mathrm{~cm}$, fished effectively followed by 14 and $13.5 \mathrm{~cm}$, which could be inferred from the predominant occurrence of positive residuals. In the case of hook study, residual plots (Fig. 3) revealed that the fishing powers of hook No. 5 performed well followed by 8 and 6 . The performance of the mesh $(14.5 \mathrm{~cm})$ and hook (No. 5) may be due to abundance of larger sized fishes in the environment and single mode of capture. No difference could be observed in the fishing power between meshes and hooks under both the assumptions in log-normal and gamma model unlike other two models viz., normal scale and normal location. The inability of differentiating the effect of fishing power in both log and gamma models may be due to confounding of fishing power between the assumptions (Millar and Holst, 1997). It could be well interpreted by the presence of equal number of positive and negative numbers of residuals under the assumptions of equal fishing power and fishing power proportional to mesh or hook size in these models.

Residual plots of better fit models revealed that the length groups of fishes caught were $44.5-102.5 \mathrm{~cm}$, 44.5-72.5 \& 90.5-96.5 $\mathrm{cm}$ and 28.5-42.5 $\mathrm{cm}$ by the out-performed meshes $14.5,14.0$ and 13.5 respectively. In

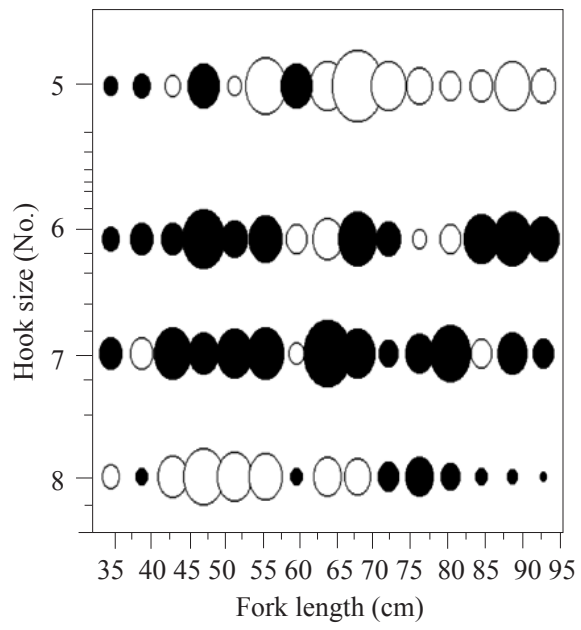

(a) the case of hook study, residual plots showed wide range of larger length class group of fish $(52.5-92.5 \mathrm{~cm})$ were caught by hook No. 5 while smaller size $(36.5-68.5 \mathrm{~cm})$ by No. 8 and larger size group of $60.5-64.5$ and $76.5-80.5 \mathrm{~cm}$ by hook No. 6. Performance of hook No. 7 was very poor. Fishing power of different mesh or hook sizes are important since catch rates vary between adjacent mesh or hook sizes to a greater extent (Hovgard et al., 1999). However, McLoughlin and Stevens (1994) expressed that assessing the equal fishing power directly at maximum selectivity was difficult.

Modal length and spread of the selection curves of different models for the different mesh and hook sizes are presented in Table 2. Modal length and spread of the selection curves increased with mesh and hook sizes in all the models except for normal location model where spread is fixed over the mesh size (Santos et al., 1995). However they varied between assumptions of equal fishing power and fishing power proportional to mesh or hook size. In the mesh selection study, the estimated modal length and spread of the better fit model were $65.4-72.7 \mathrm{~cm}$ and 7.03-7.81 respectively under the assumption of fishing power proportional to mesh size.

In the case of hook selection study, the estimated modal length and spread of the better fit normal scale model were 49.9-95.9 cm and 11.68-22.41 respectively under equal fishing power. Modal lengths obtained through better-fit normal scale models for both the gears were higher than the modal lengths obtained from other models. However, the spreads varied between models tested. Stergiou and Erzini (2002) found that modal lengths worked out based on SELECT method differed from the estimation of modal length obtained by Petrakis

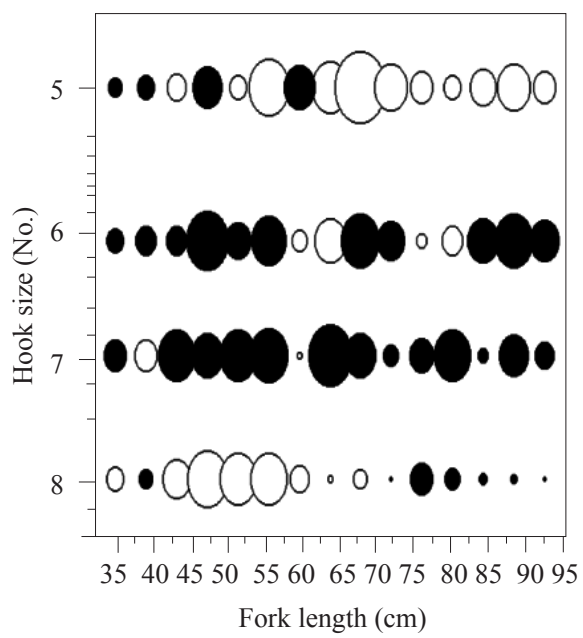

(b)

Fig. 3. Residual plots of selectivity curves of better and best fit models for different hook sizes and fishing power (area of the circle is proportion to square of the residual 
Table 2. Modal length and spread of gillnets and hook selectivity curves of various models for Carangoides fulvoguttatus

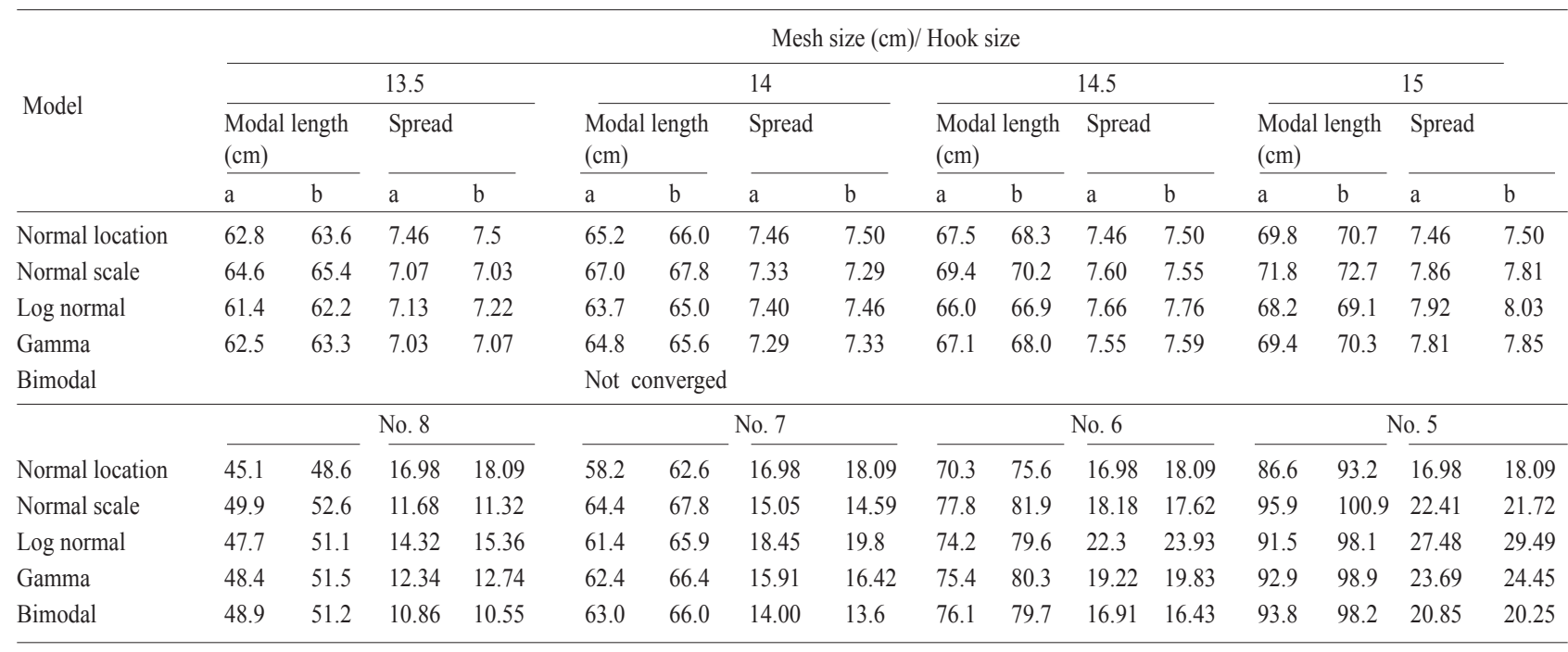

a: Equal fishing power, b: Fishing power $\alpha$ mesh/hook size

and Stergiou (1995) using Holt model. Variation in the modal length between the models in the present study also may be attributed to the differences within models and availability of wider size range of species in the sea (Engas et al., 1996). It may be common in the case of overlapping of catch distribution since the model follows principle of proportionality of Baranov (Stergiou and Erzini, 2002).

In the present study, all the statistical tools viz., model deviance, DP and residual plots employed showed poor fit in the catch data of both gears. In consequence, the better-fit models of both gears were extended to bi-normal model.

Estimated bi-modal selectivity curves and their parameters for both the gears under both the assumptions of equal fishing power and fishing power proportional to mesh or hook size are presented in Table. 1 and Fig. 3. In mesh selectivity study, the selectivity data did not converge into bi-normal model. Non-convergence of mesh selectivity data into bi-normal model may be due to single mode of capture and retention of the fish either by wedging or gilling or over-parameterisation or lack of enough quantity of data. Hence, it could be concluded that uni-modal normal scale would be best fit for the catch data of C. fulvoguttatus obtained from gillnet. It might be due to occurrence of single mode of capture as wedging which account for $89.7 \%$ and remaining by gilling (7.9\%) and entangling (2.4\%). It reinforces the fact that gillnet catch data follows normal distribution with bell shaped selectivity curve (Millar, 1995).

However, in the case of hook selection study, the better fit uni-normal model could be extended into bi-normal model. The deviance value also reduced to 96.07 under the assumption of fishing power proportional to hook size from 100.17 of normal scale model. The dispersion parameter for the bi-normal model obtained for the hook catch data was 2.4 under both the assumptions. It also revealed overdispersion of the model and moreover, it was little higher than the value of normal scale fit dispersion parameter (2.33) under equal fishing power. Overdispersion may be due to shoaling nature of carangid species as reported by Millar and Holst (1997) and it may be common problem with larger fish.

As the bi-normal model yielded good reduction in the model deviance and significant improvement in the plot of deviance residuals, it was considered superior over uni-modal (Millar and Fryer, 1999). Hovgard et al. (1999) also opined that two parameter models (uni-modal) fit the data much worse than bi-modal or multi-modal models. Selectivity curves appeared with bi-modes and differed in heights. Bi-modal curve obtained in hook selection study might be due to recruitment of mixture of different year classes into the population (Millar and Holst, 1997). This is supported by the view of Millar and Fryer (1999) that bi-modal nature of curve might be due to entanglement of fish or occurrence of multi-modal distribution of fishes. The difference in the height of the selectivity curves may be due to gear variance, though the true relative height of the curves is often confounded with relative fishing intensity parameter $\left(\mathrm{P}_{\mathrm{j}}\right)$ (Millar and Fryer, 1999) or geometric similarity of the gear. Modal length (51.2 to $98.2 \mathrm{~cm}$ ) and spread (10.55 to 20.25) of the bi-modal models increased proportionately with the hook size. Modal length obtained for every hook under fishing power proportional to hook size was greater than equal 
fishing power. The increase of modal length is proportional to the size of the hook which in turn determines the fishing power of the hook.

Residual plots of bi-modal function under both the assumption are presented in Fig. 2. Plots explained that the catch efficiency of hook No. 5 ranked first followed by No. 8 and 6 as existed in the normal scale model. Residual plots explained that the fishing power of hooks No. 5 and 6 in both uni-modal normal scale and bi-modal were almost similar unlike the hook No. 7 and 8. No significant difference was shown with normal scale model in terms of size groups caught.

Approximating the selection curves into different models may vary from species to species and rely on the model chosen for fitting the curves. The study revealed that the optimum mesh and hook size for capturing C. fulvoguttatus are $14.5 \mathrm{~cm}$ and No. 5 respectively. The optimum size of gear for the fishery was derived based on model analysis especially residual analysis from the selectivity data unlike the conventional method. Selectivity curve of gillnets and hooks of the present study are assumed as bell shaped uni and multi-modal type respectively. True model for hook is difficult to establish. However, different models may give good fit but it may be influenced based on fish behaviour and catching process. Present study indicated that gillnets could be better selective than hooks since gillnets showed clear size selection with larger mesh sizes catching larger fishes.

\section{References}

Anon. 1999. Report of state fisheries department of Tamil Nadu for the year 1998-99, Directorate of Fisheries, Chennai, $28 \mathrm{pp}$.

Alverson, D. L., Freeberg, M. H., Pope, J. G. and Murawski, S. A. 1994. A global assesment on fisheries bycatch and discards. FAO Fisheries Technical Paper, No. 339, RAO, Rome, 223 pp.

Baranov, F. I. 1948. Theory and assessment of fishing gear Theory of fishing with gillnets. Translated from Russian, $45 \mathrm{pp}$.

CONSTAT 1998. GILLNET Software, Denmark, WWW.Constat.dk.

Engas, A., Lokkeborg, S., Soldal, A. V. and Ona, E. 1996. Comparative fishing trials for cod and haddock using commercial trawl and longline at two different stock levels. J. North-west Atla. Fish. Sci., 19: 83-90.

Fujimori, Y. and Tokai, T. 2001. Estimation of gillnet selectivity curve by maximum likelihood method. Fish. Sci., 67: 644-654.

Holst, R., Madsen, N., Poulsen, T. M., Fonseca, P. and Campos, A. 1994. Manual for gillnet selectivity, XIV/1810/C1/94, $43 \mathrm{pp}$.

Hovgard, H., Lassen, H., Madsen, N., Poulsen, T. M. and Wileman, D. 1999. Gillnet selectivity for North Sea Altantic cod (Gadus morhua): model ambiguity and data quality are related. Can. J. Fish. Aquat. Sci., 56 (7): 1307-1316.

McCullagh, P. and Nelder, J. A. 1989. Generalised linear models, $2^{\text {nd }}$ edn. Chapman and hall, London, $511 \mathrm{pp}$.

McLoughlin, K. J. and Stevens, J. D. 1994. Gillnet mesh selectivities for two species of commercial carcharhinid sharks taken in northern Australia. Aust. J. Mar. Freshwat. Res., 45: 521-534.

Millar, R. B. 1995. The functional form of hook and gillnet selection curves cannot be determined from comparative catch data alone. Can. J. Fish. Aquat. Sci., 52(5): 883-891.

Millar, R. B. and Freyer, R. J. 1999. Estimating the size selection curves of towed gears, traps, nets and hooks. Rev. Fish. Biol. Fish., 9: 89-116.

Millar, R. B. and Holst, R. 1997. Estimation of gillnet and hook selectivity using log-linear models. ICES. J. Mar. Sci., 54: 471-477.

Otway, N. M. and Craig, J. R. 1993. Effects of hook size on the catches of undersized snapper, Pagrus auratus. Mar. Ecol. Prog. Ser., 936: 9-15.

Petrakis, G. and Stergiou, K. I. 1995. Gillnet selectivity for Diplodus annularis and Mullus surmuletus in Greek waters. Fish. Res., 21: 455-464.

Santos, M. N., Monteiro, C. C. and Erzini, K. 1995. Aspects of the biology and gillnet selectivity of the axillary seabream (Pagellus acorne, Risso) and common Pandora (Pagellus erythrinus, Linnaeus) from the Algarve (South Portugal). Fish. Res., 23: 223-236.

Stergiou, K. I. and Erzini, K. 2002. Comparative fixed gear studies in the cyclades (Aegean sea): Size selectivity of small-hook long lines and monofilament gillnets. Fish. Res., 58: 25-40. 